\title{
Una canción de tiempo detenido: el recuerdo de Isolation de John Lennon
}

\author{
Cristian Eduardo Secul Giusti \\ Facultad de Periodismo y Comunicación Social, Universidad Nacional de La Plata. \\ cristiansecul@gmail.com \\ Fecha de finalización: 25 de agosto de 2020 \\ Recibido: 25 de agosto de 2020 \\ Aceptado: 9 de noviembre de 2020 \\ DOI: https://doi.org/10.26422/aucom.2020.0902.sec
}

\section{Resumen}

El artículo expone un análisis discursivo de la canción Isolation (Aislamiento), compuesta por John Lennon y publicada en el disco John Lennon/Plastic Ono Band en diciembre de 1970. El acercamiento a la lírica permite repensar el actual contexto de pandemia y subrayar la potencia de la letra de rock como escena de reflexión, exposición de los temores y también expectativa. Asimismo, resulta posible reflexionar sobre el discurso interpelador del rock y profundizar su singularidad política, poética y social en el actual escenario de crisis sanitaria que obligó al aislamiento o distanciamiento social en todo el planeta.

La revisión de huellas enunciativas se efectuó a partir de un proceso de relevamiento y estudio mediado por tematizaciones y procedimientos deícticos que subrayaron fenómenos recurrentes en distintos rasgos discursivos. La clave consistió en encontrar indicios reveladores de regularidades significativas en relación con la tematización del aislamiento, la construcción de un nosotros inclusivo, la constitución de un colectivo ellos antagonista y la manifestación de una narrativa de temor y expectativa.

Del mismo modo, la formulación de preguntas habilitó la exploración de la lírica y articuló las categorías de análisis (la deixis y la tematización) en relación con una perspectiva discursivo-enunciativa: ¿cuáles son las características del contexto? ¿Cómo se inscriben las personas del discurso en la estrategia enunciativa? ¿Qué hablantes se inscriben en la letra? ¿Qué estrategia discursiva resulta predominante en la tematización del aislamiento?

La canción, producida y publicada en un escenario distinto y hace cinco décadas atrás, logra resignificar de todos modos los ánimos en torno al encierro, pensamientos relacionados a la soledad, temores referidos al presente y el futuro y expectativas de lucha, a fin de comprender el presente, ejercitar una reflexión sobre la situación pandémica y también augurar futuros posibles desde la cultura.

Palabras clave: cultura rock, COVID-19, John Lennon, pandemia, discurso, letras de rock. 


\section{A song about frozen time: remembering Isolation by John Lennon}

\section{Abstract}

This article offers a discursive analysis of the song "Isolation," written by John Lennon and released as part of the John Lennon/Plastic Ono Band album in December 1970. Through a close reading of the lyrics, we can rethink the current pandemic context and appreciate how a rock song can be a space for reflection, expectation, and the acknowledgement of fear. At the same time, we can meditate on how rock, as a discourse, engages with its listeners, as well as on the political, poetic, and social singularity of this musical genre in our current health crisis, which has forced millions around the globe into isolation and social distancing.

To this end, we carried out a revision of enunciative traces, doing so through a survey and study organized around thematic categories and deictic processes, which highlighted recurring phenomena in various discursive traits. The goal was to identify significant trends in the theme of isolation, the construction of an inclusive "us" and a collective and antagonistic "them," and the weaving of a narrative of fear and expectation.

Likewise, we formulated questions that allowed us to explore the lyrics and articulate categories of analysis (deixis and thematization) within a discursive-enunciative perspective. These questions included: What are the features of the context under analysis? How do those involved in the rock discourse fit into the enunciative strategy? What speakers are embedded in the song lyrics? And what discursive strategy predominates in the theme of isolation?

John Lennon's song - written, produced, and released in a different context than ours, five decades ago - manages to resignify our emotions and fears regarding confinement, solitude, the present, the future, and the struggles expected ahead, allowing us to understand the present reflect on the pandemic situation, and envision possible futures through the works of culture.

Keywords: rock culture, COVID-19, John Lennon, pandemic, discourse, rock lyrics.

\section{Uma música do tempo parado: A memória de "Isolation", de John Lennon}

\section{Resumo}

O artigo apresenta uma análise discursiva da música "Isolation" ("Isolamento"), composta por John Lennon e publicada no álbum John Lennon / Plastic Ono Band, em dezembro de 1970. A abordagem da letra permite repensar o contexto atual de pandêmica e destacar a força da letra do rock como cenário de reflexão, exposição de medos e também expectativa. Da mesma forma, é possível refletir sobre o discurso questionador do rock e aprofundar sua singularidade política, poética e social no atual cenário de crise de saúde que forçou o isolamento ou distanciamento social em todo o planeta.

A revisão dos traços enunciativos foi realizada a partir de um processo de levantamento e estudo mediado por tematizações e procedimentos dêiticos que evidenciaram fenômenos recorrentes em diferentes traços discursivos. A chave consistia em encontrar indícios reveladores de regularidades significativas em relação à tematização do isolamento, à construção de um "nós" inclusivo, à constituição de um coletivo antagônico e à manifestação de uma narrativa de medo e expectativa.

Da mesma forma, a formulação de perguntas possibilitou a exploração do lírico, e articulou as categorias de análise (a dêixis e a tematização) em relação a uma perspectiva discursivo-enunciativa: Quais são as características do contexto? Como as pessoas do discurso se inserem na 
Austral Comunicación

Volumen 9, número 2 (Diciembre de 2020): 325-347. ISSN 2313-9129

\begin{abstract}
estratégia enunciativa? Quais alto-falantes estão inscritos na carta? Que estratégia discursiva predomina na tematização do isolamento?

A música, produzida e publicada em um ambiente diferente e há cinco décadas, consegue redefinir o clima em torno do confinamento, pensamentos relacionados à solidão, medos relacionados ao presente e ao futuro e expectativas de luta. Desse jeito, temos a possibilidade de entender o presente, refletir sobre a situação pandêmica e também prever futuros possíveis a partir da cultura.
\end{abstract}

Palavras chave: cultura rock, COVID-19, John Lennon, pandemia, Discurso, letras de rock.

\title{
Introducción
}

La irrupción del COVID-19 generó conmoción a escala global y provocó una serie de reflexiones en el ámbito privado y en el universo público mediático, académico, empresarial, cultural y político. La estrategia del aislamiento social preventivo y sus correspondientes dimensiones diferentes forjaron un análisis de subjetividades y distinciones referidas al encierro, la soledad, la distancia y la potencialidad del arte como campo cultural de cercanía. Esa lectura permitió advertir divergencias de contexto y de apreciación, más allá de que la enfermedad nos ubique aún en una zona de amenaza reiterada y vigente.

En este sentido, las nociones de "lazo social”, “politicidad”, “distribución estatal”,"'resistencia" y/o "aislamiento" se volvieron palabras clave que potenciaron distintos destinos en las elucubraciones. Desde el terreno cultural, la música se consolidó como una compañía elemental en virtud de su cualidad notable de interacción e interrelación en el escenario de pandemia y crisis de las relaciones. A raíz de su dimensión artística, volvió a fortalecerse como medio de comunicación de emociones que "proporciona una perspectiva acerca de cómo las personas comunican sus percepciones, sus respuestas y su comprensión del mundo a sí mismas y a los demás" (Rebernak y Muhammad, 2009, p. 269).

En tanto arte y creación, la música ofrece una visión personal sobre la realidad que envuelve al artista y configura pareceres, vivencias y experiencias que conmueven y conmocionan a las recepciones. En esa práctica cultural, por tanto, se integra un sentido comunicacional que interroga sobre identidades y disputas políticas. En palabras de David Hesmondhalgh (2015), la música vigoriza una expresión política, vinculada a la "sustentación de una sociabilidad pública" y, por consiguiente, "la cultura musical desarrolla valores e identidades que contribuyen a la deliberación, la democracia y la política de maneras sustanciales" (pp. 30-31).

En este aspecto, la música rock se configura como un fenómeno trascendental y disruptivo de la cultura contemporánea que propone un eje identitario y se legitima a partir de distintas conceptualizaciones en sus discursos (por ejemplo, a causa de la autenticidad, la confrontación, la expresión o la retórica). En su relación con la cultura 
Cristian Eduardo Secul Giusti

Una canción de tiempo detenido: el recuerdo de Isolation de John Lennon

popular, el rock se desarrolla en el seno de la industria del entretenimiento y resignifica sus propias prácticas y actividades. Así, plantea una propuesta estética y una particular visión cultural del mundo que, con vaivenes, mantiene ciertas tensiones con la sociedad de consumo.

El rock se postula, entonces, como un sistema discursivo que supera al género musical y que comparte (en sus intenciones y producciones) los efectos de la comercialización e industrialización de la producción musical a partir de negociaciones y luchas en la arena cultural. Desde sus discursos y prácticas, instituye una sucesión de representaciones sociales (ideológicas) sobre la creación musical y la vida de los jóvenes en sociedad.

El accionar antiautoritario y emancipatorio que presenta el rock permite pensarlo como un movimiento que se preocupa por expresar un discurso con diferentes tonalidades de impugnación y crítica. En consecuencia, se enmarca en una trama que se alimenta de "negociaciones, rechazos y apropiaciones; de símbolos que se hacen circular privada y públicamente; de una pluralidad de prácticas y de experiencias; de eventos vividos y significados; de textos que abarcan y exceden las experiencias" (Rodríguez, 2010, p. 13)

Las manifestaciones de la cultura rock se nutren de una gran corriente discursiva que resignifica sus prácticas y transforma, desde ya, las propias condiciones de producción. Las canciones forman parte de una discursividad plausible de analizar en relación con las cotidianidades, virtudes, sentidos y vacilaciones en tiempos agitados. El discurso presente en las letras incluye un conjunto complejo de actos lingüísticos, sonoros y visuales que se construyen en un ámbito de práctica social de un modo dialéctico y dialógico.

En esa línea, el artículo expone un análisis discursivo del tema Isolation (Aislamiento), compuesto por John Lennon y publicado en el disco John Lennon/ Plastic Ono Band en diciembre de 1970. El estudio permite repensar el actual contexto de pandemia y subrayar la potencia de la letra de rock como escena de reflexión, exposición de los temores y también expectativa. De esta manera, es posible reflexionar sobre el discurso interpelador del rock $\mathrm{y}$, asimismo, profundizar en su singularidad política, poética y social en el actual escenario de crisis sanitaria que obligó al aislamiento o distanciamiento social en todo el planeta.

El acercamiento a la canción posibilita repensar los procesos sociales que atraviesan la vida, la cultura y el arte mismo, considerando una fórmula que vincula al autor con su contexto de enunciación y la potencialidad de su contenido. Su abordaje histórico también propone una instancia didáctica de contextualización, representación y manifestación de lenguajes diversos a partir de discursos líricos de un fenómeno cultural, transgeneracional y vigente como el de la cultura rock. 
Las líricas se instauran "como piezas discursivas atravesadas por una coyuntura histórica y por una memoria del pasado reciente que dan cuenta de diferentes nociones de construcción colectiva y/o individual en sociedad" (Secul Giusti, 2017, p. 9). $\mathrm{Al}$ respecto, la dimensión comunicativa de su estudio se entiende como un proceso participativo de construcción y reconstrucción de sentidos que admite la continua interpretación y reinterpretación de intenciones explícitas y no explícitas en un marco enunciativo (Valentino y Fino, 2015, p. 9).

En tanto, la comunicación no es concebida como un proceso único de transmisión de datos o traspaso armónico, sino como una trayectoria interactuada que articula experiencias comunes y referencias culturales incluidas en discursos.

Las letras de rock proponen un acto de comunicación que se caracteriza por construir una visión del mundo desde el discurso producido, provocar sentido y generar lazos comunicantes. Esto mismo evidencia una perspectiva crítica que se encuentra presente desde los inicios del campo de estudio en comunicación en América Latina y que permite reflexionar desde la intervención analítica. De esta manera, se complejizan los modos en los que las subjetividades se comunican, producen y narran a fin de manifestar una expresión correspondiente y contextualizada (Fasano, Jiménez, Ramírez y Ruiu, 2002).

El estudio mismo incluye un análisis del lenguaje sin aislarlo de su contexto comunicativo y cultural, es decir, sin apartar las características de su función de mensaje y del sentido que la vehiculiza. De ese modo, el concepto de "discurso" designa un nivel de análisis y se presenta como sistema de significación que oscila entre lo explícito y lo implícito, una combinación entre los modos de decir de significar y un conjunto de posibles significados que circulan en sociedad (Londoño Zapata, 2012).

\section{El discurso de las canciones}

A más de cincuenta años de su nacimiento, la cultura rock continúa siendo una práctica social que se retroalimenta a partir de debates, complejidades y expresiones que rearman estéticas y modos de concebir los acontecimientos de la vida social. De esta forma, permite la convergencia de perspectivas que postulan un estado de incomodidad, de reconfiguración identitaria dentro de la industria cultural y de tensión constante con las reglas del sistema a partir de la crítica y el desafío.

Las líricas presentan operaciones discursivas que activan pensamientos aleatorios, centrífugos y marginales que se enfrentan a la aceptabilidad, las modalidades tolerables y las jerarquías impuestas por los mandatos sociales. Justamente, construyen el escenario social, lo objetivan y comunican representaciones. Aun desde su diálogo con la industria cultural y el comercio, complejizan los instrumentos de control social y generan intersticios en los que se filtran sus propias temáticas y repertorios: producen 
Cristian Eduardo Secul Giusti

Una canción de tiempo detenido: el recuerdo de Isolation de John Lennon

un escenario de debate en torno a las instancias hegemónicas de los discursos sociales y colocan en crisis intereses estructurales, tradiciones y posiciones adquiridas.

A partir de su discurso, las canciones de rock proponen producciones sociales de sentido que formulan representaciones del mundo; exponen lugares comunes, conversaciones triviales, espacios dogmáticos y discutibles de la denominada "opinión pública”; y también plantean eslóganes o especulaciones estéticas, filosóficas y políticas de los acontecimientos. Actúan, además, como diálogos teatrales o cinematográficos que se hacen voz e impactan en el quehacer del lector-espectador-escucha. Abordadas desde la figuración abstracta y la alegoría o desde el realismo, se encuentran atravesadas por huellas subjetivas que interrogan lo real, lo legitimado y lo construido como statu quo, e incluyen rasgos temáticos, compositivos y estilísticos que determinan núcleos semánticos y construcciones en torno a mundos posibles (Conde, 2007, p. 16).

Las líricas poseen un discurso de expresión artístico-cultural que rescata identidades o épocas que manifiestan (y proponen) posturas políticas e ideológicas. Así, se consolidan como un género discursivo que integra a las circunstancias enunciativas en las que circula el discurso y configura no solo propósitos, sino también su materialización. La comprensión de su instancia genérica permite abordar un análisis discursivo que articula lo textual con un contexto a partir ciertos indicadores que sitúan la instancia comunicativa. Desde ese plano, es plausible relevar cómo los sujetos se vinculan con el mundo, la historia y la ideología en términos enunciativos.

$\mathrm{El}$ análisis del discurso de las canciones es multidisciplinario e intertextual. Actúa como una caja de herramientas que permite entender las prácticas en las que el empleo de la oralidad y la escritura forman parte de las actividades de vida. Ese estudio incluye el rastreo de los rasgos de subjetividad que atraviesan a los hablantes y advertir así las valoraciones, concepciones del mundo y/o marcos ideológicos que se presentan. El estudio discursivo admite prosperar, reflexiva y sistemáticamente, una producción de sentido en torno a los actos de comunicación que definen y establecen nuevos límites, espacios, contactos y síntesis. El intento de rescate desde una configuración crítica se encuentra presente desde los inicios del campo de estudio y viabiliza un posicionamiento social desde la intervención analítica en comunicación.

En ese marco, el análisis discursivo tiene por objeto dar cuenta del funcionamiento de los fenómenos lingüísticos en su uso y su forma de construir sentido social en sociedad (Charaudeau, 2009). Esto mismo contribuye a actuar sobre las problemáticas de la constitución de la subjetividad en el proceso de la vida socio-cultural y atraviesa los modos en los que las subjetividades se comunican, producen y narran desde el espacio social, además de tensionar con los factores hegemónicos. Sobre este punto, Marc Angenot (2010) señala que los componentes hegemónicos producen lo social como discurso e imponen dogmas, fetiches, tabúes y "canon de reglas", inscriptos bajo una 
asociación de poderes, restricciones y medios de exclusión que remiten a arbitrariedades formales y temáticas. De esta manera, se articulan las pautas de lo decible, se conjugan los dispositivos de reprobación que bloquean lo indecible y se habilita un campo de temáticas, saberes aceptables y parámetros retóricos, narrativos o argumentativos.

Las letras de canciones, en tanto género discursivo, se presentan como un "lugar social" y permiten posicionar así un campo discursivo que organiza la perspectiva analítica. Por esto mismo, Dominique Maingueneau (1999) remarca que, en todos los casos, se debe poner en evidencia el carácter central de la noción de "género discursivo", puesto que "a título de 'institución discursiva' desbarata toda exterioridad simple entre 'texto' y 'contexto'. El dispositivo enunciativo corresponde a la vez a lo verbal y a lo institucional" (p. 21). Así, la noción genérica es pensada desde una perspectiva que supera la noción sociológica y su posicionamiento describe las condiciones sociales y la escena que se construye a través de la propia palabra.

El discurso es, en simultáneo, un cuadro y un proceso. Se distingue entre una escena englobante (que le confiere una disposición pragmática al texto) y un marco que es definido por los discursos particulares. En efecto, el género discursivo entraña relaciones dialógicas y polifónicas (remarcadas por ecos e hilos de voces) y plantea una noción de interacción discursiva (según la construcción, la estructuración y la producción discursiva). Del mismo modo, el lazo polifónico y dialógico es atravesado por prácticas sociales, cuya cimentación discursiva es colectiva, histórica, política, dinámica, dialéctica, temporal y situacional.

En este escenario, los distintos discursos confluyen y dialogan desde diferentes posturas y configuran tanto la práctica discursiva como el género discursivo. El enunciado se encuentra relacionado con los eslabones anteriores y con los posteriores de la comunicación discursiva: "Se construye desde el principio tomando en cuenta las posibles reacciones de respuesta para las cuales se construye el enunciado [...] Un signo importante (constitutivo) del enunciado es su orientación hacia alguien, su propiedad de estar destinado" (Bajtín, 1982, p. 285).

\section{La conciencia del rocanrol}

La letra como concepto contiene una materialidad que permite establecer formaciones discursivas constituidas por un número circunscrito de enunciados, por ello, es entendida como un acto que resulta fundamental para comprender el género discursivo en el que se enmarca enunciativamente. En términos de Bárbara Ferris Graves y Donald McBain (1972), la voz lírica de la cultura rock floreció hacia la década del 60 a partir del intento obstinado de los hombres y las mujeres de penetrar en el sentido de la existencia "en función de la relación de voces de la calle, voces que entrelazan los 
Cristian Eduardo Secul Giusti

Una canción de tiempo detenido: el recuerdo de /solation de John Lennon

sonidos del presente con las viejas cuestiones de la relación del hombre con su amada, su sociedad y con el cosmos" (p. 59).

Intrínsecamente, la canción roquera advierte un rechazo a la autoridad o al conservadurismo y se expresa más que nada por su sentido de la fórmula: un estribillo intenso y marcado, una consigna sucinta y recordable e incluso un título representativo. Claude Chastagner (2012) señala que el rock deslumbra cuando presenta textos concisos y permite alusiones líricas que, sobre todo, evitan el discurso pedagógico y la definición sesuda:

\begin{abstract}
El rock brilla [...] cuando prefiere el grito y el aullido a la demostración, la emoción a la reflexión, la sugerencia a la explicación. El rock es, ante todo un arte del eslogan que, simplista y superficial a primera vista, condensa un máximo de sentido, de impacto emocional y simbólico en una forma exigua y excitante [...] Bajo la forma minimalista del eslogan, la emoción constituye una apropiación de la palabra, una réplica, un diálogo en sentido bajtiniano, opuesto a la concepción foucaultiana de discurso desencarnado, dominador y único (p. 59).
\end{abstract}

El lenguaje de las canciones representa un aspecto importante de las reglas del género letra de rock: el empleo de un coloquialismo con léxico llano, gráfico, inmediato y concreto, y la exposición de un tono informal, comprensible y resumido en su estribillo (con mínimas recurrencias metafóricas). Por tanto, esto juega un rol primordial, porque la rebelión del rock es, ante todo, de simbología textual y de las palabras, mediadas por estrategias retóricas que ocupan un lugar muy importante en la cultura rock (Chastagner, 2012, p. 53).

Las letras roqueras incluyen transformaciones, tomas de conciencia y emergencias que revalorizan un nuevo estado de ánimo. A su modo, plantean una estrategia retórica que permite estudiar la época y la contemporaneidad en clave cultural y transgeneracional. Sobre este punto, Serge Denisoff y Mark Levine (1971) les atribuyen dos modalidades de acción a las canciones de rock. Por una parte, la función movilizadora, que facilita la participación y que se vincula directamente con las canciones orientadas al compromiso político y el movimiento colectivo. Por otra, la función retórica, que brinda un acceso persuasivo y de articulación de opiniones en los oyentes de canciones o lectores de letras de rock.

La estrategia retórica tiene un carácter performativo y parte de la capacidad del lenguaje para producir discursos persuasivos y, asimismo, para provocar una relación con el contexto sociocultural determinado. En este sentido, su discurso está construido por discursos sociales, caracterizados por aspectos retóricos que articulan alianzas, orientan pensamientos, aplacan emociones y/o guían acciones de seducción y excitación (Perelman, 1989). Por esto, la operación retórica se vincula con una formación de estereotipos que instauran posicionamientos, integrados a discusiones o perspectivas del marco histórico que las convoca. Los procedimientos persuasivos y vinculantes con 
el contexto resultan relevantes porque atraviesan nociones ideológicas enlazadas con estadios o estructuras que atañen a la existencia de diversas generaciones.

La estrategia sobresale en la discursividad social porque hace posible la consolidación de una trama comunicativa constituida por diálogos y contrastes de opiniones en un ámbito masivo. La lírica del rock, en este aspecto, acentúa su perspectiva argumentativa que articula en relación con la pluralidad de voces y dirige sus discursos a una comunidad de oyentes-lectores-espectadores. Sobre este punto, las letras particularizan una forma de retórica de lenguaje hablado y estrategia movilizadora (Frith, 2014) que depende de los modos de articulación, el contenido verbal, el tipo de lenguaje utilizado y el significado simbólico.

\section{Las huellas del aislamiento}

En el caso de Isolation y su relectura en tiempos de COVID-19, la revisión de huellas enunciativas para este trabajo se efectuó a partir de un proceso de relevamiento y estudio mediado por tematizaciones y procedimientos deícticos que subrayaron fenómenos recurrentes en distintos rasgos discursivos. La clave consistió en encontrar indicios reveladores de regularidades significativas en relación con la tematización del aislamiento, la construcción de un nosotros inclusivo, la constitución de un colectivo ellos antagonista y la manifestación de una narrativa de temor y expectativa.

Particularmente, Isolation es una canción que aparece en el primer trabajo solista de John Lennon, uno de los líderes principales de The Beatles, una de las bandas más importantes y legendarias de la cultura rock a escala global. A cuarenta años de su muerte (el 8 de diciembre de 1980), el músico y pilar de la música popular continúa representando la conciencia del rocanrol y es, más aún, un paradigma de ambición creativa y honestidad biográfica:

Casi todo lo que hoy damos por sentado en el mundo del espectáculo y la música popular lo hizo primero o mejor Lennon: la composición de canciones brutalmente autobiográficas, los reportajes llenos de confesiones detalladas, el uso del megaestrellato como una herramienta para promover cambios sociopolíticos. Desde el estudio de grabación, primero con los Beatles en los 60, después como solista y en escena con Ono, Lennon desafió, todo el tiempo y sin temor, los límites de la expresión personal (Fricke, 2000, p. 54).

La obra John Lennon/Plastic Ono Band, editada y producida por el reconocido artista Phil Spector en 1970, tiene canciones muy relevantes en la historia del artista, las cuales refieren a procesos personales de música y situaciones complejas de su biografía. Por citar cuatro ejemplos, en Mother aborda sus traumas familiares e infantiles; en God expone una alternativa a la utopía de la década del 60; en I found out critica el oportunismo en la política y el mundo del espectáculo; y en Love destaca su situación pasional y amorosa con Yoko Ono, su compañera hasta el día que murió. 
Cristian Eduardo Secul Giusti

Una canción de tiempo detenido: el recuerdo de Isolation de John Lennon

\begin{abstract}
Plastic Ono Band no es un disco sencillo de escuchar, pero es precisamente la cruda intensidad que transmite la catarsis pública de Lennon lo que atrapa al oyente y no lo suelta hasta el último surco del disco (o la última secuencia digital, si prefieren...). Esa mezcla de sensaciones, donde conviven la angustia y el alivio de dejar de ser Beatle John, el quiebre de la fantasía idealista de los ' 60 , sus fantasmas del pasado (el abandono de su padre y la muerte prematura de su madre), todo ese bagaje emocional que John arrastraba fue volcado en este álbum (Rosso, 2020, párr. 28).
\end{abstract}

La letra de Isolation, en especial, expone el miedo a la soledad y problematiza sobre la sensación de temor, incertidumbre y, a su vez, de expectativa en un contexto agresivo y de cierre de la mirada utópica de la cultura rock. Esa diatriba, referida a la situación política mundial, con la guerra de Vietnam como referencia ineludible y los conflictos armados en países centrales y también periféricos, expone también la situación de Lennon como compositor y agente de discusión.

Durante el lanzamiento del disco John Lennon/Plastic Ono Band, el movimiento rock se encontraba en un proceso de reconfiguración y de transformación de voluntades: del idealismo hippie al éxito masivo de nuevas bandas y las vinculaciones directas con la industria cultural. De esta forma, se evidenciaba un clima de cambio y disolución: "Separación de The Beatles, gran despedida de Woodstock de la Era de Acuario, final del flower power, avance de las drogas duras sobre la marihuana. Pero la música como el arte más representativo de la cultura joven no cesó" (Pujol y Satas, 2003, p. 70). Asimismo, como sostiene críticamente Philippe Paraire (1992),

\footnotetext{
En la primera fila de los héroes cansados hay que citar a Bob Dylan, que ni se presenta en Woodstock ni hace una sola canción sobre la guerra del Vietnam. Mick Jagger arrastra a los Rolling hacia el rock comercial y se contenta con administrar eficazmente la "empresa" Stones. Los Beatles, separados -fue el gran drama del año 1970, a la vez simbólico y esperado-, intentan emprender carreras en solitario (p. 136).
}

Esta situación conflictiva provocó una decepción general en la perspectiva de Lennon, no solo con el universo del espectáculo, sino también en la exposición de su arte y en los modos de dirigirse hacia sus críticos. Estos últimos le reclamaban cierta falta de idiosincrasia por compartir su vida con la artista japonesa Yoko Ono (criticada por la prensa especializada y los seguidores de la banda de Liverpool).

En el mito de Lennon tiene mucho que ver, como ocurre casi siempre, la calidad de la obra. Lennon fue un músico lúcido y un letrista agudo. Derrochaba ese tipo de ingenio cortante que suele dar en el blanco. Parecía arrogante, pero es que la arrogancia es una de las constantes del rock [...] En realidad, él, como casi todos los que son adorados, se creen depositarios de la confianza universal (Gómez Pérez, 1994, p. 69).

Isolation se inspiró en la psicoterapia denominada "terapia primal", creada por el terapeuta estadounidense Arthur Janov y celebrada por revisitar traumas de la infancia y la juventud a fin de alcanzar una liberación personal. Si bien fue tildada de superfi- 
cial, simplista o pasatista por los estudios académicos de psicología, Janov escribió su libro The Primal Scream en 1970 y adquirió aún más relevancia luego de que Lennon y Ono iniciaran un breve tratamiento. Esa experiencia, a fin de cuentas, motorizó las composiciones y los testimonios expuestos en ciertas líricas del álbum, como Mother, Instant karma, God y la que se puntualiza en este trabajo.

Como bien señala el periodista Alfredo Rosso (2020), el terapeuta Janov sostenía que las neurosis estaban provocadas por las ausencias paternas o de contención familiar:

Su terapia consistía en alentar al paciente a "gritarle" a sus padres ausentes, en un intento de exorcizar sus fantasmas. John y Yoko se entusiasmaron tanto con el libro que le escribieron a Janov, proponiéndose como pacientes. Janov aceptó tratarlos con la condición de que siguieran estrictamente sus instrucciones, entre las cuales figuraban el dejar de fumar, tomar alcohol y consumir drogas (Rosso, 2020, párr. 23-24).

Este primer álbum solista se registró en los estudios EMI, localizados en Abbey Road, el lugar que supo aglutinar a The Beatles en su última etapa y que sirvió para titular uno de sus discos más famosos: Abbey Road, publicado en 1969. Más allá de las distintas temáticas manejadas por el músico en su obra pos-Beatles, su retórica evidenció un tránsito que oscilaba entre el amor y el desamor, la injusticia y la paz, la guerra y el aislamiento.

Tras la separación de The Beatles, Lennon sostuvo la lucha cultural y política por encima de la iconoclasia de la utopía sesentosa y rompió con las imágenes más quiméricas, a fin de forjar una perspectiva particular sobre lo que significa la existencia en tiempos revueltos, la vida feliz y las vivencias de un artista acosado por la mirada de los otros.

Lennon transmitía la verdad de que se necesitaba alguna imagen utópica (sea la utopía de
la enorme y borrascosa pasión que perseguía con su esposa o la de una canción en la que
decía exactamente lo que quería decir y era comprendido). Esta imagen de utopía no era
solipsista [...] Siempre asumía la existencia de otras personas, de cuya presencia depen-
día, se tratara de Yoko Ono, o de vos, o de mí (Marcus, 2013, p. 218).

En palabras de Emile Benveniste (1977), la expresión da cuenta de una relación con el mundo, tiene una referencia central y "así la enunciación es directamente responsable de ciertas clases de signos que promueve, literalmente, a la existencia" (p. 87). Entendiendo este contexto, el análisis de Isolation permitió un acercamiento a la subjetividad (a partir de las marcas presentes en los textos) y un estudio referido a elementos lingüísticos que no tienen el valor de una información que se comunica, sino "que son huellas que deja en el enunciado el sujeto que lo ha producido" (Marín, 2008, p. 78).

El acto enunciativo admite la puesta en funcionamiento de la lengua desde una instancia individual. Por ello, el concepto de "enunciado" refiere al proceso de enun- 
Cristian Eduardo Secul Giusti

Una canción de tiempo detenido: el recuerdo de /solation de John Lennon

ciación (en este caso, ficcionado en clave lírica de rock), realizado por enunciadores y destinado al enunciatario. Si bien existen abordajes que vinculan e incluso comparan al enunciado como unidad que presenta la misma función de la oración, su diferencia es notable. La oración puede cumplir el papel de enunciado en tanto represente una idea completa y conclusa, que, a su vez, se enfrente a otros enunciados ajenos y esté contextualizada por la situación extra-lingüística (escenario, ambiente, prehistoria).En efecto, una oración se transforma en enunciado en el momento en el que no necesita relacionarse con otras oraciones propias del contexto discursivo del sujeto hablante para adquirir significado y sentido:

La gente no hace intercambio de oraciones ni de palabras en un sentido estrictamente lingüístico, ni de conjuntos de palabras; la gente habla por medio de enunciados, que se construyen con la ayuda de las unidades de la lengua que son palabras, conjuntos de palabras, oraciones; el enunciado puede ser constituido tanto por una oración como por una palabra, es decir, por una unidad del discurso (principalmente, por una réplica del diálogo), pero no por eso una unidad de la lengua se convierte en una unidad de la comunicación discursiva (Bajtín, 1982, p. 264).

En los enunciados convergen condiciones específicas que incluyen trazos (marcas, marcadores, índices, indicadores, pistas) articulados para que sean interpretados por las recepciones. Se pueden destacar tres momentos que se relacionan entre sí en la totalidad del enunciado. En primer lugar, es posible abarcar, entender y sentir la voluntad discursiva de los hablantes. En segundo término, se advierte la intencionalidad de la organización expresiva. Por último, se aprecian las formas genéricas y estructurales, en las que la intención discursiva de los hablantes, con su individualidad y subjetividad, se aplica y se adapta al género escogido, se forma y se desarrolla dentro de una forma genérica determinada (Bajtín, 1982).

En el presente artículo, la concepción de "enunciado", sumado al repertorio de la tematización y la deixis, diagramó parámetros contextuales que permitieron analizar la concepción de "aislamiento", la construcción del sujeto discursivo y su participación e inclusión en los enunciados. De esta manera, en el discurso lírico se verifican las implicaciones del hablante particular y de las recepciones en esa distribución textual.

El procedimiento de la tematización incluyó un asunto de atención insistida, que centralizó la significación y la trascendencia discursiva. Así, el espectro sobre el "aislamiento" se estableció como marco articulador y organizador del discurso. La búsqueda de la tematización se refirió a un problema de actuación lingüística, tomando en consideración el modo en el que los enunciados fueron planificados y organizados con una intencionalidad particular. A partir de la puesta en común del material tematizado, fue posible analizar un repertorio de estrategia discursiva que dio cuenta del tratamiento enunciativo y la estructura correspondiente. El concepto de "aislamiento", entonces, se 
comprendió como un elemento tematizado y como un tópico que admitió la apertura de interpretaciones en relación con los contextos y los marcos enunciativos.

La identificación de deícticos personales, por su parte, permitió advertir los planos de inscripción enunciados en la lírica, a fin de señalar el contexto y las personas del discurso que conviven en su escenario de comunicación. El estudio de la deixis recuperó la situación de enunciación, remarcando la importancia del pronunciamiento, la posible recepción, el momento plausible insertado y el lugar probable de manifestación para alcanzar la producción de sentido.

Las formulaciones de ciertas preguntas habilitaron la exploración de la lírica y permitieron articular las categorías de análisis (la deixis y la tematización) en relación con una perspectiva discursivo-enunciativa: ¿quiénes participan de la situación comunicativa? ¿Cuáles son las características del contexto? ¿Cómo se inscriben las personas del discurso en la estrategia enunciativa? ¿Qué hablantes se inscriben en la letra? ¿Qué estrategia discursiva resulta predominante en la tematización del aislamiento? ¿Qué posibles efectos de sentido provoca esa construcción?

\section{En la inmovilización}

La recuperación actual de la canción Isolation sobresale abiertamente porque se inserta en un año atravesado por la distancia social y el confinamiento obligatorio provocado por el virus COVID-19. En un contexto de saturación por los efectos pandémicos, forjó distintas consideraciones sobre el aislamiento preventivo y el distanciamiento social. A estos efectos, tanto en los medios tradicionales como en las redes sociales proliferaron discursos de diversa índole (autoritarios, oscurantistas o autorreflexivos) que se envolvieron en distintas tramas vinculadas a las noticias falsas, las crisis informativas y los conflictos económicos, sociales, políticos y culturales de los Estados.

En la reunión vertiginosa de opiniones y consideraciones sobre el escenario actual, el presente pandémico fue leído desde aristas opuestas y también analizado con mayor o menor tino. En el caso de la propuesta europea o anglosajona, se vio una voluntad de categorización y de definición a fin de superar la convulsión y detectar un fenómeno lo más rápido posible. Más aún, se pretendió desmontar el horizonte y destacar el futuro más próximo, pensado desde un lugar más agónico y voraz.

Para ejemplificar, en su artículo "Aprendiendo del virus", Paul Preciado (2020) realizó una historización de los fenómenos pandémicos, enfatizó en los modos sociales de enfrentamiento y resistencia y llamó a apagar "los móviles", desconectar internet y hacer "el gran blackout" para generar una contrariedad y oponerse a todo tipo de dominio temporal, espacial, económico y político sobre los cuerpos.

Tenemos que aprender colectivamente a alterarlos. Pero también es preciso desalinearnos. Los Gobiernos llaman al encierro y al teletrabajo. Nosotros sabemos que llaman a la des- 
Cristian Eduardo Secul Giusti

Una canción de tiempo detenido: el recuerdo de Isolation de John Lennon

colectivización y al telecontrol. Utilicemos el tiempo y la fuerza del encierro para estudiar las tradiciones de lucha (párr. 31).

Por su parte, Byung-Chul Han (como se cita en Rendueles, 2020) manifestó que la pandemia dio lugar a una sociedad de la cuarentena en la que se pierde toda experiencia comunitaria y se padece la intercomunicación: "Seguimos comunicándonos, pero sin ninguna experiencia comunitaria que nos haga felices. El virus aísla a las personas. Agrava la soledad y el aislamiento que, de todos modos, dominan nuestra sociedad" (Chul Han, como se cita en Rendueles, párr. 15). En esa línea, Gabriela Cabezón Cámara (2020) remarcó la necesidad de no entregarse a una "vida online" que continúe por los mismos caminos del capitalismo tardío: "Estamos quietos, aislados en un tiempo que se vuelca sobre sí mismo. Al fin y al cabo, es una forma de tregua. Sintamos. Pensemos. Digamos no. No lo hagamos si preferimos no hacerlo" (p. 198).

Horacio González (2020) buscó examinar los mecanismos relacionados con las medidas de aislamiento y ensayó un posible destino de la humanidad en función de los cursos del capitalismo y sus nociones de degradación y apariencia. Por tanto, señaló que en este tramo histórico, el concepto de movilización total de la filosofía alemana se encuentra invertido y "ahora la inmovilización general es la forma orgánica del pensamiento político" (párr. 3).

Asimismo, Maurizio Lazzarato (como se cita en Bogado, 2020) expresó que el panorama del aislamiento se dispone de un modo apocalíptico y que el encierro experimentado se asemeja a una prueba de crisis ecológica o atómica contra un enemigo invisible: "bajo la amenaza organizada por los responsables de la situación que ha surgido. El capitalismo contemporáneo generaliza la guerra contra los vivos” (párr. 13).

Horacio Machado Aráoz (2020) señaló que el aislamiento hizo tomar conciencia de la comunidad como necesidad vital, de la centralidad de los vínculos y la cooperación social; de la vida como interdependencia, como-proceso-en-común:

$$
\begin{aligned}
& \text { La "anormalidad" de estos días de paro, nos advierte sobre la entropía y la disfuncionali- } \\
& \text { dad intrínseca a la normalidad que hemos creado. Las muertes que produce se comparan } \\
& \text { con las que, a la vez, evita; nos hace registrar las otras múltiples y generalizadas formas de } \\
& \text { matar que se encuentran vigentes en la rutina del mundo contemporáneo (p. 171). }
\end{aligned}
$$

A escala global, la canción de Lennon resonó de un modo distinto en la clave pandémica por COVID-19 con el objeto de "rellenar el vacío existencial que puede sobrevenir al encierro, $y$ en ese sentido por supuesto [...] Aislamiento, cuarentena, distanciamiento, calles vacías, encierro, monólogos interiores, palabras y expresiones que definen estos días extraños" (Pintos, 2020, párr. 1). En ese sentido, la potencia musical y cultural de Isolation permite resignificar el aislamiento desde el arte y revivir tópicos, enunciados, miedos, imágenes y conceptualizaciones que se integran a la singular actualidad. 
La lírica, producida y publicada en un escenario distinto y hace cinco décadas atrás, logró resignificar de todos modos los ánimos en torno al encierro, los pensamientos relacionados a la soledad, los temores referidos al presente y al futuro y las expectativas de lucha. A fin de comprender el presente, ejercitar una reflexión sobre la situación pandémica y también augurar futuros posibles, es pertinente retomar la discursividad planteada en Isolation en pos de vincular su intencionalidad con las visiones variadas pero también de profunda lectura distópica y revalorización temerosa- que circularon en los discursos sociales tras la irrupción del COVID-19 en el mundo.

Al respecto, la situación del aislamiento propició la aparición de voces que manifestaron aspectos variados de acuerdo con los países, las poblaciones y las idiosincrasias de las sociedades. Por esta razón, como sostiene María Pía López (2020), el tiempo del aislamiento social preventivo y obligatorio incluye, en cierto modo, "un tiempo detenido, sujeto a un puro presente que debe ser agenciado en términos estrictos de necesidad y preservación. Detenido el tiempo, interrumpido el movimiento por la ciudad" (p. 69).

\section{La sombra de la incertidumbre}

En línea con sus consideraciones retóricas y filosóficas, la cultura rock se muestra alejada de todo índice de fosilización de vida y de experiencia, y se aparta de la quietud y el estancamiento de existencia. En ese sentido, construye una identidad vinculada al rol de lo íntimo, con la escucha personalizada, parcializada y personal que trastoca ciertas nociones sobre lo emancipatorio y las supedita a un desarrollo aislado y encerrado en momentos de agresión o aversión social.

Tomando en consideración su espectro temático, algunas intencionalidades se relacionan con una poética de escape en la soledad y en la introspección. A raíz de ello, la reflexión sobre la protección y la emancipación refuerza inquietudes y recupera tensiones desde los aislamientos sociales: se expanden las críticas hacia los medios de comunicación y se amplifica la escritura, la composición, la intertextualidad con nociones literarias, políticas, cinematográficas y la exposición de acciones colectivas y/o individuales en relación con los consumos.

En Isolation (releída y analizada en tiempo verbal presente), la voz lírica construida por John Lennon (en tanto sujeto empírico del discurso) se posiciona desde un nosotros inclusivo que manifiesta una instancia reflexiva y de resguardo sobre una situación de encierro. Desde ese plano, se evidencian sentires dolorosos vinculados al temor, la soledad excluida, la desazón y la ausencia de certezas en un mundo que, según se destaca en el interrogante inicial, desconoce la situación de las personas que reflexionan sobre el terror y lo padecen: ¿Acaso no saben que estamos muy asustados? 
Cristian Eduardo Secul Giusti

Una canción de tiempo detenido: el recuerdo de /solation de John Lennon

Ese nosotros inclusivo empleado exhibe una disposición reflexiva que integra a Lennon y a Ono en un mismo pensamiento, y destaca la opaca situación de su aislamiento, repetido como motor esencial durante toda la letra: cuatro veces. Sobre este punto temático, en una de sus entrevistas posdisolución de The Beatles, el músico remarcó la importancia de poner su cuerpo en las líricas, tal vez como modo de comprometerse más aún con sus consideraciones existenciales:

\section{Realmente nunca me gustó escribir canciones en tercera persona acerca de gente que vivía en departamentos de cemento y esas cosas. A mí me gusta la música en primera persona, pero, por mis cuelgues, sólo de cuando en cuando escribía sobre mí. Ahora, todo lo que compuse habla de mí. Ese soy yo, y nadie más. Y por eso me gusta. Es real. Eso es todo (Lennon, como se cita en Wenner, 1998 p. 76).}

La función apelativa de la canción se potencia por el empleo de deícticos personales, inscriptos como indicaciones en el texto verbal (nosotros, yo, ellos). Así, la vinculación entre un sujeto hablante (que se desplaza entre la primera persona del singular y la primera persona del plural) y la recepción (en tanto escucha o lector de cultura rock) subraya un entramado textual, de perspectiva dialógica. Por un lado, se evidencia un hablante construido enunciativamente, que se comporta como locutor y se responsabiliza del contenido textual. Se lo introduce como testigo de los hechos que narra o como portavoz fundamental de la narrativa.

En segundo término, una interlocución que se representa discursivamente mediante referencias distintivas y que se advierte desde dos instancias convocantes: como destinatario de canción y como referencia ajena del texto (intratextual). En última instancia, se advierte la figura de una tercera persona que se diferencia de la construcción del vos y del yo y que se posiciona como recepción oposicional que actúa contra ambos. Así, el nosotros inclusivo, al que representa el intérprete, se configura como la voz de la protesta contra un elemento opresor representado por el ellos antagonista (Vela Delfa, 2014, p. 5)

Por tanto, la utilización del colectivo ellos refiere a una otredad agresiva y antagonista que está fuera de los límites de la convivencia y ofrece una postura netamente exasperante. En términos de Ernesto Laclau (2009), ese antagonismo revela una posición política que incorpora un enfrentamiento con un poder que obstaculiza y paraliza el imaginario de transformación

El antagonismo presupone la incompatibilidad entre elementos opuestos, mientras que la coherencia al interior de una estructura implica la complementariedad entre sus momentos internos [...] Por antagonismo se entiende una relación entre fuerzas enemigas, de modo tal que la negatividad pasa a ser un componente interno de esa relación. Cada fuerza niega la identidad de la otra. Pero en una oposición real no tenemos este tipo de negación, esta interrupción mutua de las identidades (p. 25). 
Esos contrarios presentes en la lírica buscan dañar y afectar al núcleo doliente que reflexiona en contexto de encierro y aislamiento y que también sobrelleva cierta soledad. Por tanto, la responsabilidad negativa recae sobre esa otredad que se torna afectante y trabaja en desmedro de los cuerpos.

La fragilidad de ese nosotros inclusivo está marcada por las voluntades de destrucción que imperan a su alrededor: existe un ellos que propone azotar sus expectativas, causar dolores (después de haber causado tanto dolor) y ocluir todo cambio de estructura social (el aislamiento permite repensar los basamentos sociales). También, ese discrepante es exhibido de un modo inmutable ante su propia gravedad y enunciado, en cambio, desde la primera persona: Yo no espero que comprendas; Sos un simple humano, una víctima de la locura. Adicionalmente, el eje de la inscripción vuelve al eje del nosotros inclusivo y remarca el desequilibrio propuesto por ese antagonismo (Están intentando derrumbarnos $)^{1}$ y profundiza una denuncia de desigualdad y desemejanza ante la crisis (Tenemos miedo de estar solos, todos tienen que tener un hogar).

\section{Una expectativa mesurada}

Durante el período 1962-1968, el rock se ocupó de reclamar en nombre de los otros, de la comunidad o de la generación, esa misma que devino luego de Elvis, Little Richard y Chuck Berry, por citar tres ejemplos. A partir de 1969, sin embargo, la demanda roquera se posicionó de un modo menos grandilocuente, con más líricas imperiosas desde la individualidad, angustiosas y con temores singulares que hablaban de diferentes rupturas. La urgencia, por lo que se advierte a la distancia, no era otra "que la del encuentro, la de una escucha, la de una confrontación con otra individualidad, otro cuerpo" (Chastagner, 2012, p. 197).

Aun así, en los tiempos de grabación y publicación de su primer disco solista, Lennon abordó la cultura rock como su púlpito y el principal motor para que su esperanza se eche a rodar, más allá de las complejidades y los inconvenientes en el escenario personal y colectivo. Si bien estaba peleado con el ideario de The Beatles, creía en el rock como música humanista, sincera, desafiante: "Siempre me gustó el rock sencillo. Estuve bajo el efecto del ácido y me volví psicodélico, igual que todo el resto de mi generación, pero en realidad me gusta el rock \& roll, y me expreso mejor con el rock" (Lennon, como se cita en Wenner, 1998, p. 76).

En Isolation se evidencia una voluntad de transformación y un "grito primal" que integra a la esperanza, aun a sabiendas de las opacidades y los trasfondos. Esa noción de horizonte no se insinúa desde la alucinación, sino desde la advertencia y la toma de

\footnotetext{
Este pasaje puede referirse a las militancias públicas por la paz y desde la cama, realizadas por Lennon y Ono en 1969. Estos acontecimientos efectuados en Ámsterdam y Montreal despertaron distintas críticas, tanto dentro de la música como por fuera.
} 
Cristian Eduardo Secul Giusti

Una canción de tiempo detenido: el recuerdo de /solation de John Lennon

conciencia generalizada. Por un lado, aparecen menciones a la integridad y perseverancia: El sol jamás desaparecerá, y, por otro, surge la sensación de temor e inquietud: Al mundo podría no quedarle muchos años. En esa primera demanda se apela al sustantivo "sol" con el propósito de crear una figura luminosa y de color que resplandece, salva y contiene en los momentos de distanciamiento. Del mismo modo, se incorpora una noción de inestabilidad y de certidumbre más bien opaca, que constituye una alarma: Pero al mundo podría no quedarle muchos años.

Desde ese plano, el contexto sociopolítico de la propia lírica es expuesto como una "locura" exterior y una vorágine que arrastraba las desesperanzas del "simple humano". En esa línea, "el mundo", en tanto concepto que incluye un problema, es un pueblo cercano, tangible y, a la vez, una probabilidad de cataclismo: El mundo es solo un pequeño pueblo.

A partir de una decisión de relato en tercera persona, se señala además una situación voluntativa y también quebradiza que incluye a Lennon y a Ono, y también refuerza la marca indefensa de su discurso: Tan solo un niño y una niñita intentan cambiar el mundo. Esa introducción episódica narrada en tercera persona incluye un breve pasaje del yo/nosotros al ellos (no antagonistas, en este caso, sino protagonistas del relato), que provoca un salto momentáneo que no altera el discurso e incluye un cambio de pronombres gramaticales que permite permanecer "en un sistema de la persona" (Barthes, 1966, p. 20).

La mezcla de sistemas se siente evidentemente como un recurso facilitador. Este recurso,
exagerado, puede llegar a utilizarse como celada [...] todo sucede como si en una misma
persona hubiera una conciencia de testigo, inmanente al discurso, y una conciencia de
criminal, inmanente a lo referido: sólo el torniquete, abusivo de ambos sistemas permite
el enigma (1966, p. 20).

Esta mención regresiva que refiere al niño y a la niña se relaciona directamente con las sesiones que mantuvieron con el terapeuta Janov, en las que exploró sentimientos acerca de sus relaciones, el fallecimiento de su madre, la disolución de su grupo insigne y la resonancia de ser un símbolo de resistencia cultural:

\footnotetext{
"Las canciones de John vinieron de dentro suyo", dice Yoko. "Fueron escritas en base a lo que aprendimos durante la terapia primal. Renovó nuestra vitalidad; John fue una persona diferente después de eso. Comenzó a abrirse. Según Ono, esta brutal introspección también provocó un vuelco musical. Él estaba desnudando su alma, así que todo lo que hicimos era desolado [...] Es simplemente un chico pequeño en una habitación". John anunció su independencia con estas canciones (Diehl, 2004, p. 13).
}

La imagen que incluye cambiar el mundo los expone como dos figuras que enfrentan a un espectro entero y que, por tal motivo, también desean modificarlo, trastocarlo, llevarlo a otro lugar de desarrollo. En ese cuadro, hay una actitud persuasiva y 
Austral Comunicación

Volumen 9, número 2 (Diciembre de 2020): 325-347. ISSN 2313-9129

voluntativa. Ese mundo, mencionado anteriormente como un pequeño pueblo, tiene sus contingencias positivas, pero también sus complejidades.

El aislamiento, en tanto, es un lugar que admite temores, pero que también forja emergencias de reflexión a futuro. Como concepto, actúa como clave entre las estrofas y es un punto crucial de repetición porque enmarca tanto las perplejidades como los deseos y las preocupaciones en torno a un alrededor que se construye agresivo e iracundo. La euforia parece dejada de lado y se abre paso la nostalgia y la profunda búsqueda de un entendimiento.

El discurso propuesto subraya aún hoy un carácter no solo prescriptivo, sino también productor de condiciones de cambio de las prácticas comunicacionales de la sociedad de época. De acuerdo con ello, ciertas palabras y/o expresiones presentes en la canción incluyen evaluaciones a partir del nombramiento de ciertos objetos (sustantivos) o hechos del mundo que refiere. De esta manera, se integra un acercamiento a un escenario de incertidumbres y expectativas exteriorizadas a partir de enunciaciones simbólicas y/o explícitas sobre el encierro y los temores. El miedo experimentado en la lírica, en términos de Paul Virno (2013), se alimenta de una espiral de socorros reflexivos respecto al estado de las cosas "potencialmente amenazante: el temor que me corta la respiración se forma siempre, más que por un peligro determinado, por un relato alarmado que me hago de él; entonces, es siempre temor del propio temor" (p.23).

Siguiendo esta línea, Isolation propone, además, búsquedas en pos de diferenciarse de la solemnidad y acercarse a la diversidad y a la expresión. Se construye así un discurso de centralidad autobiográfica que postula demandas en los términos cotidianos y también político-universales. En este sentido, también se incorpora una discursividad de tensión con ciertas prácticas de aquellos ubicados como antagonistas y se profundiza un aspecto distintivo que se relaciona con los alcances del placer, la escapatoria y la abulia en un ámbito de vida urbana. Este repertorio remarca articulaciones fragmentarias y relatos de vacilación que profundiza una estrategia enunciativa de gran confusión. La construcción discursiva propuesta en la lírica consiente, desde una revisión actual y contemporánea, otras versiones de los hechos y habilita nuevas opiniones sobre la temática del aislamiento, en tanto reflexión sobre el presente y el futuro.

\section{Conclusiones}

Estas líneas finales remarcan la importancia del estudio discursivo de las letras de rock y su correspondiente implicancia en el contexto de publicación y la posterior recepción de su contenido. Por esta razón, el presente apartado no propone concluir el trabajo ni considerar un cierre de perspectiva, sino recuperar las parcialidades expuestas en cada instancia del artículo para ser pensadas a futuro. 
Cristian Eduardo Secul Giusti

Una canción de tiempo detenido: el recuerdo de Isolation de John Lennon

El análisis enunciativo de Isolation permitió estudiar las estrategias discursivas articuladas por agentes únicos, válidos para identificar objetos y acontecimientos dentro del mundo lírico. El acercamiento admitió un esfuerzo interpretativo y una voluntad de rastreo a fin de reconstruir una escena del pasado que impacta (desde ángulos distintivos) en el presente pandémico.

Por consiguiente, el artículo se diagramó desde una perspectiva contextual, subrayando la relación entre la canción de John Lennon y los diferentes discursos que circularon en un escenario de inicio de década (1970) y la vinculación actual que se efectuó en función del momento de crisis sanitaria y distanciamiento social. Ante esto, cobra relevancia la cultura rock en tanto manifiesto transgeneracional y herramienta para advertir diagnósticos y decisiones en torno a vivencias y experiencias.

El análisis posibilitó el desentrañamiento de sentidos que no aparecen de manera explícita y que van más allá de lo temático y de los tópicos frecuentes. Así, las inquietudes se orientaron hacia el desarrollo del contexto, la vinculación de la cultura rock como una condición de producción relevante para analizar los discursos de las líricas.

A partir de la estrategia enunciativa desplegada, el análisis reforzó las valoraciones de un entorno cultural e ideológico que, a cincuenta años, repercuten en esta actualidad de un modo diferente, aunque igual de potente. La mirada discursiva coordinada y relevante en relación con las problemáticas de aislamiento y sus contenidos tuvo presente la consideración del contexto y la constante asimilación de las propias coordenadas de la cultura rock.

Siguiendo este camino de exposición, el análisis de Isolation mostró el surgimiento, circulación y consolidación de la letra de rock como herramienta plausible de ser estudiada. Por esta razón, fue posible advertir representaciones de vida o de existencia e, igualmente, una apuesta en torno a relaciones sociales, inquietudes y sensaciones de creer, sentir y vivir en un escenario conmovido, tanto en 1970 como en el actual 2020. El estudio concedió una proximidad interpretativa que habilitó una nueva época de desafíos y complicaciones referidas a los temores, las soledades y los aislamientos.

En virtud de la perspectiva analítica, se construyó una aproximación descriptiva que, entre rasgos y huellas, fue construyendo un corolario de intencionalidades y subjetividades. En tanto, la reflexión sobre el rol de la cultura rock no significa solamente pensar los discursos de aislamiento en 1970 o 2020, sino promover también una abstracción crítica en torno al alcance de un fenómeno generacional y colectivo que, desde sus discursos, convive ( $\mathrm{y}$, en algunos casos, padece contradictoriamente) y se relaciona de un modo inédito con la cultura oficial, sus mecanismos de articulación y las experiencias de la cotidianidad.

Resulta imposible, entonces, dar por finalizada una interpretación o una mirada respectiva sobre las instancias modales que diagnostican un ideal de expresión. Por esto 
Austral Comunicación

Volumen 9, número 2 (Diciembre de 2020): 325-347. ISSN 2313-9129

mismo, la improbabilidad de cierre se destaca por dos cuestiones esenciales: en primer lugar, el estudio del discurso no tiene una articulación concluyente, sino que es más bien dialógica y discutible. En segundo lugar, existe una contradicción en la tentativa de finalizar un trabajo que recupera nociones tanto de la historia reciente como de la cultura y, en este caso, de un presente pandémico que persiste en nuestras experiencias.

\section{Referencias}

Angenot, M. (2010). El discurso social. Los límites de lo pensable y lo decible. Buenos Aires: Siglo XXI.

Bajtin, M. (1982). Estética de la creación verbal. México: Siglo XXI.

Barthes, R. (1966). Introduction à l'analyse structurale des récits. Communications, 1(8), 1-27.

Benveniste, E. (1977). El aparato formal de la enunciación. En Problemas de lingüística general II (pp. 82-95). México: Siglo XXI.

Bogado, F. (2020). Maurizio Lazzarato debate con el pensamiento del 68 y plantea las posibilidades del cambio global. Página/12. Obtenido el 19 de agosto de 2020 de https://www.pagina12.com. ar/258645-maurizio-lazzarato-debate-con-el-pensamiento-del-68-y-plante.

Cabezón Cámara, G. (2020). Episodio 2: El capitalismo está desnudo. En El futuro después del COVID-19 (pp. 195-199). Buenos Aires: Presidencia de la Nación.

Charaudeau, P. (2009). Discurso y Contexto. Revista Discurso \& Sociedad, 3(2), 253-279.

Chastagner, C. (2012). De la Cultura Rock. Argentina: Paidós.

Conde, O. (Comp.). (2007). Poéticas del rock (Vol. I). Buenos Aires: Marcelo Héctor Oliveri Editor.

Denisoff, R. y Levine, M. (1971). The one dimensional approach to popular music: a research note. The Journal of Popular Culture, 4(4), 911-919.

Diehl, M. (2004). La realización de Plastic Ono Band. Rolling Stone (Edición Especial de Colección: Los 500 mejores discos de todos los tiempos), 6(73), 13.

Farris Graves, B. y McBain, D. (1972). Lyrical Voices: approaches to the poetry of contemporary song. Nueva York: John Wiley.

Fasano, P., Jiménez, J., Ruiu, A. y Ramírez, A. (2002). La realidad social como pieza comunicacional. VI Congreso Latinoamericano de Ciencias de la Comunicación "Ciencias de la Comunicación y Sociedad: un diálogo para la Era Digital. Enfrentando la brecha entre academia y sociedad". ALAIC 2002. Santa Cruz de la Sierra, Bolivia. Obtenido de https://webcache. googleusercontent.com/search?q=cache:UJHmXC7xGmYJ:https://ccyo.files. wordpress.com/2009/08/la-realidad-social-como-pieza-comunicacional. $\mathrm{doc}+\& \mathrm{~cd}=3 \& \mathrm{hl}=\mathrm{es}-419 \& \mathrm{ct}=\mathrm{clnk} \& \mathrm{gl}=\mathrm{ar}$. 
Cristian Eduardo Secul Giusti

Una canción de tiempo detenido: el recuerdo de Isolation de John Lennon

Fricke, D. (2000). Dame algo de verdad. Rolling Stone, 3(32), 53-56.

Frith, S. (2014). Ritos de la interpretación: sobre el valor de la música popular. Buenos Aires: Grupo Planeta.

González, H. (2020). La inmovilización. Buenos Aires: Lobo Suelto. Obtenido el 19 de agosto de $2020 \mathrm{de} \mathrm{http://lobosuelto.com/la-inmovilizacion-horacio-gonzalez/.}$

Gómez Pérez, R. (1994). El rock: 40 años de música. Madrid: Editorial El Drac.

Hesmondhalgh, D. (2015). ¿Por qué es importante la música? Buenos Aires: Paidós.

Janov, A. (1970). The primal scream: Primal therapy: The cure for neurosis. Nueva York: Dell Publishing Company.

Laclau, E. (2014). Los fundamentos retóricos de la sociedad. Buenos Aires: Fondo de Cultura Económica.

Londoño Zapata, O. (2012). Poliedros discursivos: Miradas de los Estudios del Discurso. Córdoba: ALED.

López, M. P. (2020). La vida en cuestión. En Svampa, M., Cragnolini, M., Ribeiro, S., Aizen, S., López, M. P., Rodríguez Alzueta, E., Spregelburd, R., Petruccelli, A., Mare, F., Pasquinelli, L., Bilbao, B., Botto, C., Menéndez, F., Kaufman, A., Méndez, L. y Agamben, G. La Fiebre. Buenos Aires: Editorial ASPO.

Machado Aráoz, H. (2020). Imaginando un (otro) mundo pospandemia. Desafíos y posibilidades desde la Ecología Política del Sur. En Rodríguez Alzueta, E., Breilh, J., Herrero, M. B., Belardo, M., Katz, C., Acosta, A., Cajas Guijarro, J., Machado Aráoz, H., González, H., Escales, V., Cheppi, J. M., Revel Chion, A., Kordon, D., Edelman, L., Lagos, D. M., Badenes, D., Sierra Caballero, F., Giorgi, G., Gamerro, C., Link, D. y Djament, L. Posnormales. Buenos Aires: Editorial ASPO.

Marcus, G. (2013). Escritos sobre punk 1977-1992. En el baño del Fascismo. Buenos Aires: Paidós Entornos.

Maingueneau, D. (1999). Ethos, scénographie, incorporation. En Amossy, R. (ed.). Images de soi dans le discours. La construction de l'ethos (pp. 75-101). París: Delachaux et Niestlé.

Marín, M. (2008). Teoría de la lectura como proceso. Lingüística y enseñanza de la lengua. Buenos Aires: Aique.

Paraire, P. (1992). 50 años de música rock. Madrid: Ediciones del Prado.

Perelman, C. (1989). Tratado de la argumentación. La nueva retórica. Madrid: Gredos.

Pintos, G. (2020). De The Doors a Lennon: 10 canciones que reflexionan sobre el encierro y la soledad. Infobae. Obtenido el 19 de agosto de 2020 de https://www. infobae.com/cultura/2020/04/27/de-the-doors-a-lennon-10-canciones-quereflexionan-sobre-la-cuarentena-el-encierro-y-la-soledad/.

Preciado, P. (2020). Aprendiendo del virus. El País. Obtenido el 19 de agosto de 2020 de https://elpais.com/elpais/2020/03/27/opinion/1585316952_026489.html. 
Austral Comunicación

Volumen 9, número 2 (Diciembre de 2020): 325-347. ISSN 2313-9129

Pujol, S. y Satas, H. (2003). Historia de nuestro tiempo. El mundo entre 1969 y 2000. La Plata: EPC.

Rebernak, J. y Muhammad, I. (2009). Interacciones artísticas y competencias interculturales en el Mediterráneo. Quaderns de la Mediterrània, (12), 265-270.

Rendueles, C. (2020). Byung-Chul Han: El dataísmo es una forma pornográfica de conocimiento que anula el pensamiento. El País. Obtenido el 19 de agosto de 2020 de https://elpais.com/cultura/2020/05/15/babelia/1589532672_574169.html.

Rodríguez, M. G. (2010). Cultura popular: mi pie izquierdo. Revista Oficios Terrestres, 1(26), 1-17. Obtenido el 19 de agosto de 2020 de https://core.ac.uk/download/ pdf/19512596.pdf.

Rosso, A. (2020). John Lennon y su grito primal. Noticias Argentinas. Obtenido el 19 de agosto de 2020 de https://www.noticiasargentinas.com.ar/los-beatles/ john-lennon-y-su-grito-primal-n88305.

Secul Giusti, C. E. (2017). Rompiendo el silencio: la construcción discursiva de la libertad en las líricas de rock-pop argentino durante el período 1982-1989 (Tesis de Doctorado). Universidad Nacional de La Plata, Buenos Aires.

Valentino, A., y Fino, A. (2015). El discurso de la información como objeto de estudio. En Valentino, A., y Fino, A. (coords.). La información como discurso. Recorridos teóricos y pistas analíticas (pp. 4-12). La Plata: Editorial de la Universidad Nacional de La Plata.

Vela Delfa, C. (2014). Análisis enunciativo del género discursivo de la canción protesta: espacio de encuentro e interacción social. Ogigia. Revista electrónica de estudios hispánicos, (16), 71-82. Obtenido el 19 de agosto de 2020 de https://revistas.uva.es/ index.php/ogigia/article/view/3662/2958.

Virno, P. (2013). La lógica de las pasiones. Pasiones políticas. Buenos Aires: Editorial Quadranta.

Wenner, J. (1998). Rolling Stone Interview. John Lennon. Rolling Stone, 75-85. Obtenido el 19 de agosto de 2020 de https://www.lanacion.com.ar/espectaculos/ john-lennon-nid587379/. 